\title{
A numerical finite element study on connections of SFRC offshore wind towers with prestressed CFRP reinforcement and steel connectors
}

\author{
Chandan C. Gowda ${ }^{1 *}$, Fabio P. Figueiredo ${ }^{1}$, Joaquim A. O. Barros ${ }^{1}$, António Ventura-Gouveia ${ }^{2}$ \\ ${ }^{1}$ University of Minho, Guimarães, Portugal \\ ${ }^{2}$ Polytechnic Institute of Viseu, Portugal \\ Received: 03 July 2020 / Accepted: 23 November 2020 / Published online: 15 December 2020 \\ (C) The Author(s) 2020. This article is published with open access and licensed under a Creative Commons Attribution 4.0 International License.
}

\begin{abstract}
The growing need for sustainable production of electricity highlights the importance and the necessity of having higher number and more effective offshore wind towers. The rapid growth of offshore wind towers is estimated to produce $4 \%$ of electricity demands in Europe by the end of 2020 . The research described in this paper is part of a project dedicated for the development of innovative structural system using advanced materials for lightweight and durable offshore towers. Specifically, it discusses the nonlinear finite element modelling of the connection between representative prefabricated rings of offshore wind tower made by steel fibre reinforced concrete (SFRC), and prestressed by a hybrid system of carbon fibre reinforced polymers (CFRP) bars and steel strands. This connection is assured by post-tension high steel strength cables and concrete-concrete shear friction width an idealized geometric configuration of the faces in contact. The model takes into account the loads from the rotor, wind and water currents, by considering the critical loading conditions for the safety verifications of serviceability and ultimate limit states. The material nonlinear analyses are carried out with FEMIX V4.0 software, considering a 3D constitutive model capable of simulating the relevant nonlinear features of the SFRC, and interface finite elements for modelling the shear friction of the concrete-concrete surfaces in contact. The parametric analyses involve the influence on the relevant results of the SFRC fracture parameters, pre-stress level of the reinforcements, shape of interlock mechanism, friction angle and interface cohesion.
\end{abstract}

Keywords: Offshore wind tower; Material nonlinear analyses; Shear frictional and tied connections

\section{Introduction}

The developing need of energy production is draining the natural resources like oil, natural gas, coal etc., at a more rapid rate than ever. This pushes the humankind to produce more sustainable energy production for the future. Offshore wind tower, which uses the powerful wind, is one these sustainable solution to produce electricity. The first wind farm was installed in Denmark in 1991 [1]. 84\% of all offshore wind installations are located in European waters, with remaining $16 \%$ mainly in China, followed by Vietnam, Japan, South Korea, U.S and Taiwan [2].

Fig. 1 shows the global cumulative offshore wind capacity in 2017, which indicates that the production capacity has increased over $450 \%$ from 2011 to 2017 and is continuously growing. This moves the society towards a more productive, cost-efficient, sustainable and renewable energy production, reducing the carbon dioxide emissions. One of the steps in reducing these costs is by developing innovative structural systems, which is the main aim of the current research.

The proposed steel fibre reinforced concrete (SFRC) towers involve prefabricated concrete rings of high dimensions assembled on site by post-tensioned steel cables. Minor changes in design or construction process can have significant impact on these type of constructions in terms of cost and schedule savings [3]. The innovative use of composite materials in construction i.e., in support structures and foundations, will reduce fabrication and transportation efforts, resulting in the most cost effective solutions [4].

The main scope of this paper is to perform material nonlinear analysis of the connection between two representative steel fibre reinforced concrete (SFRC) prefabricated rings (of thin wall and variable diameter) of the structural system developed in the scope of the research project. The steel fibre reinforcement aims to eliminate the conventional steel bars, reducing the ring's wall thickness. These rings are prestressed with carbon fibre reinforced polymer (CFRP) bars, taking advantage of the non-corrosiveness of CFRP, while posttensioned steel cables ensure the connection between consecutive rings, providing simple, fast assembling and disassembling process in the tower's construction. However, high stress gradients are expected to occur in these anchoring zones, a concern that promoted the development of the present material nonlinear analysis.

\footnotetext{
* Corresponding author: Chandan C. Gowda, Email: chandu627@gmail.com
} 


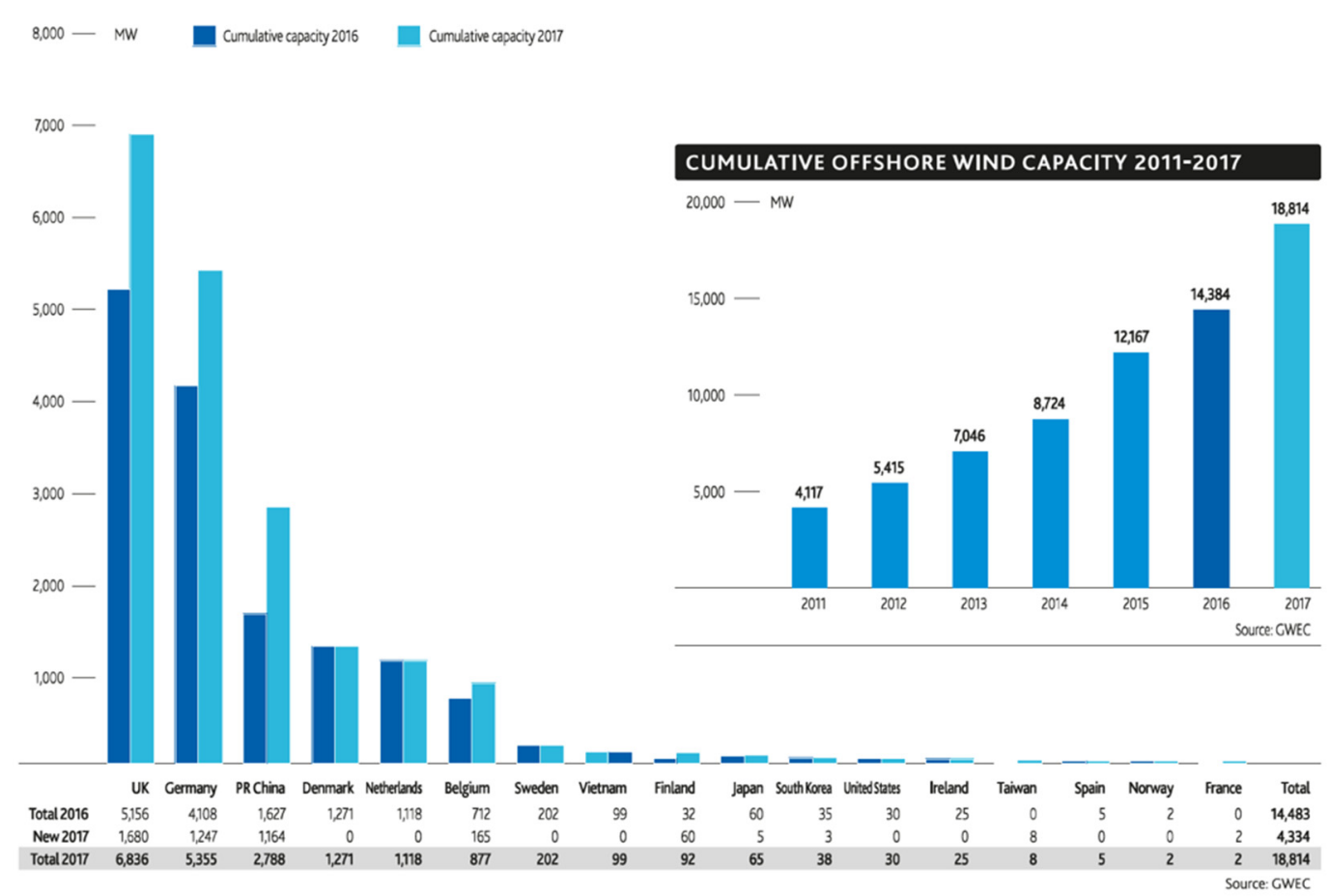

Figure 1. Global cumulative offshore wind capacity in 2017 [2].

\section{Simplified design approach}

A simplified approach for the design of offshore wind towers is adopted in this paper. The loads considered herein consist of forces acting on top of the structure due to wind passing throughout the rotor, wind pressure on the tower structure, waves slamming the tower, and loads produced by water currents on the tower structure (see Fig. 2).

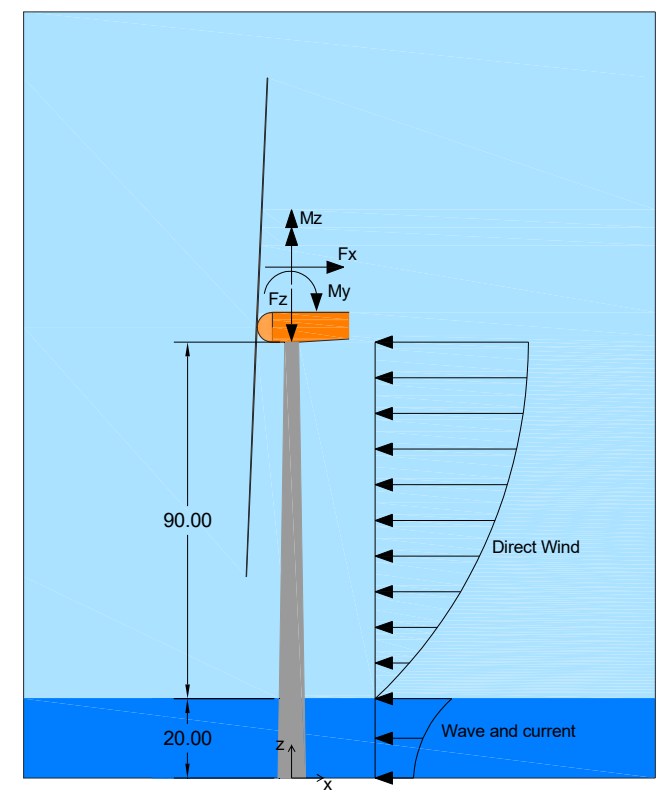

Figure 2. Applied loads (dimensions in $\mathrm{m}$ ).

Since it was not possible to obtain precise information about loads from turbine wind tower manufacturers, they were extrapolated from a $3 \mathrm{MW}$ wind turbine [5] and are presented in Table. The axial forces acting on the tower are the prestressing and gravitational loads. The wind load per unit of length, $f_{w i}[\mathrm{~N} / \mathrm{m}]$, was calculated using the following equation:

$$
f_{\text {wi }}(z)=0.5 C_{a} \rho_{\text {air }} D(z) u(z)^{2}
$$

where $\rho_{\text {air }}\left[\mathrm{kg} / \mathrm{m}^{3}\right]$ is the density of air, $C_{a}[-]$ is the aerodynamic drag coefficient (shape, surface dependent), $D(z)[\mathrm{m}]$ is the diameter of the tower cross-section at elevation $z$, and $u(z)[\mathrm{m} / \mathrm{s}]$ is the mean wind speed at elevation $z$. The wave and current loads were obtained using the semi-empirical Morison's equation:

$$
f_{M}(z)=f_{i}(z)+f_{d}(z)
$$

where $f_{i}(z)$ represents the hydrodynamic inertial load $[\mathrm{N} / \mathrm{m}]$ and $f_{d}(z)$ is the hydrodynamic drag load $[\mathrm{N} / \mathrm{m}]$. A simplified approach for the design of offshore wind towers is adopted in this paper. The loads considered consist of forces acting on top of the structure due to wind passing throughout the rotor, wind pressure on the tower structure, waves slamming the tower, and loads produced by water currents on the tower structure. The final equations used to determine the loads acting in the structure and the information about the simplified approach can be found in [6].

Table 1. Five MW wind turbine loads for serviceability and ultimate limit states (SLS, ULS).

\begin{tabular}{|l|l|l|}
\hline Parameter & $\mathrm{SLS}$ & $\mathrm{ULS}$ \\
\hline Horizontal shear force $\mathrm{F}_{\mathrm{x}}(\mathrm{kN})$ & 690 & 1585 \\
\hline Moment $\mathrm{M}_{\mathrm{y}}(\mathrm{kNm})$ & 1600 & 3677 \\
\hline Torque $\mathrm{M}_{\mathrm{z}}(\mathrm{kNm})$ & 1010 & 1789 \\
\hline
\end{tabular}

Design offshore wind towers in compliance with standards require that the structure shall satisfy ultimate, accidental, fatigue and serviceability limit state design conditions (ULS, ALS, FLS and SLS), respectively [7]. However, in this study, only 
the most unfavourable combination for the ULS is considered. The load combination given by DNV [7] is calculated using the following expression:

$$
F=1.0 G+1.35 E
$$

where $G$ are the permanent loads (tower, rotor and nacelle self-weight) and $E$ are the environment loads (wind, waves and currents).

\section{Model}

\subsection{Geometry and data}

The global height of the current tower is 110 meters, with 90 $\mathrm{m}$ above and $20 \mathrm{~m}$ below the sea level. The external radius of the ring at $z=0 \mathrm{~m}$ height (sea bed) is 3.6 meters, which reduces to $1.8 \mathrm{~m}$ (at $z=110 \mathrm{~m}$ height) at the top. The full tower consists of 10 rings, each of 11 meters high. The connection between consecutive SFRC rings is assured by post-tensioned steel cables. The cross section of this connection is subjected to loads and moments generated by the loading conditions described in the previous section, and the global analysis is discussed elsewhere [8]. According to the global analysis, the bottom most ring $(z=0-11 \mathrm{~m})$, is subjected to most unfavourable loading conditions for design purpose. As a result, the connection between the bottom two rings shown in Fig. 3, i.e., the ring resting on the sea bed and the one above, is analysed and the results are discussed in this paper. The FE model consists of the bottom full ring $(11 \mathrm{~m})$ and half of the ring above ( $5.5 \mathrm{~m}$ ), with a total height of $16.5 \mathrm{~m}$ (Fig. 3). The radius at the base of the tower is $3.60 \mathrm{~m}$ and the radius at $16.5 \mathrm{~m}$ height is $3.33 \mathrm{~m}$. Excluding the four longitudinal ribs $730 \times 600 \mathrm{~mm}^{2}$ cross section (Fig. 3b) and the circumferential rib that assures the connection between consecutive rings, the wall thickness is $100 \mathrm{~mm}$. The cross section of the circumferential rib has the geometry shown in Fig. 4 . The connection is assured by 4 post-tensioned steel cables (one per each longitudinal rib) with a pre-stress level of $60 \%$ and 8 post-tensioned steel connectors distributed along the perimeter of the circumferential rib with a pre-stress level of $60 \%$ (see Fig. 3b). The surface of connection is inclined on both the top and the bottom rings to provide additional shear resistance, shown in Fig. 4. Each ring is prestressed with 16 carbon fibre reinforced polymer (CFRP) bars of $30 \mathrm{~mm}$ diameter placed in the centre of the SFRC wall (Fig. 3b). a

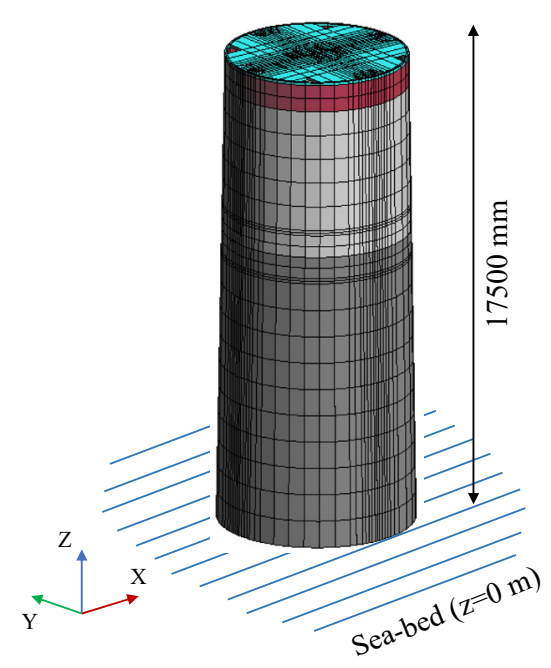

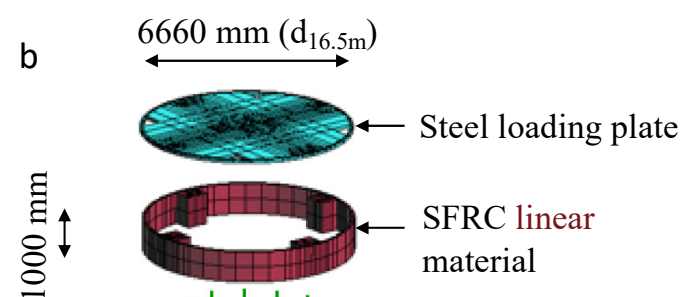
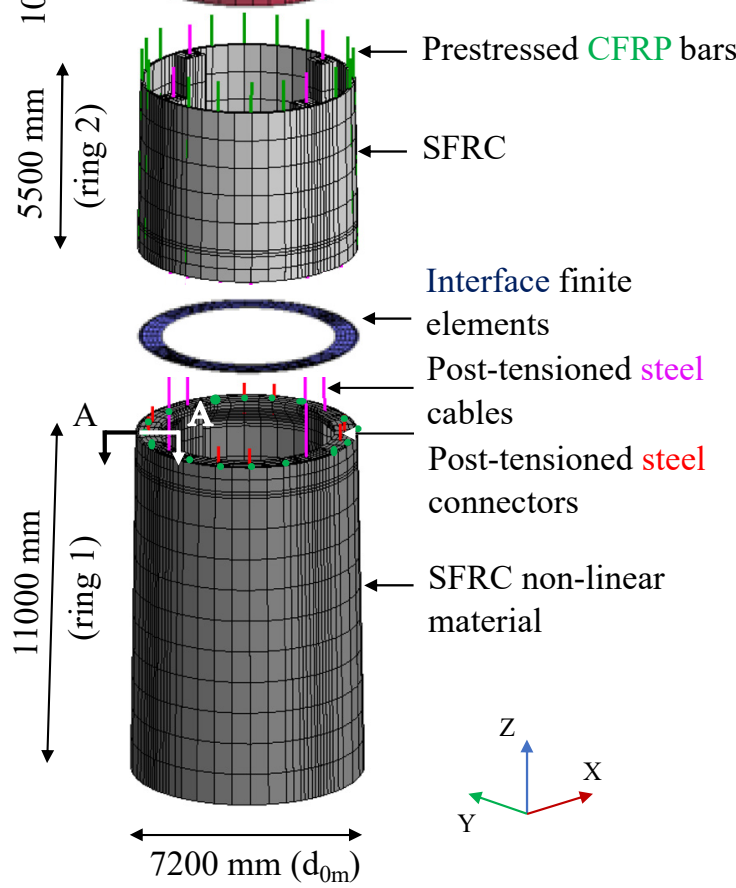

Figure 3. Model "t_s1": (a) Full model and (b) Components of the model. 


\subsection{FEM attributes and material properties for the constitutive model}

A 3D multidirectional smeared crack model [9] available in FEMIX 4.0 is used for the numerical simulations. GiD software is used as a pre- and post-processor.

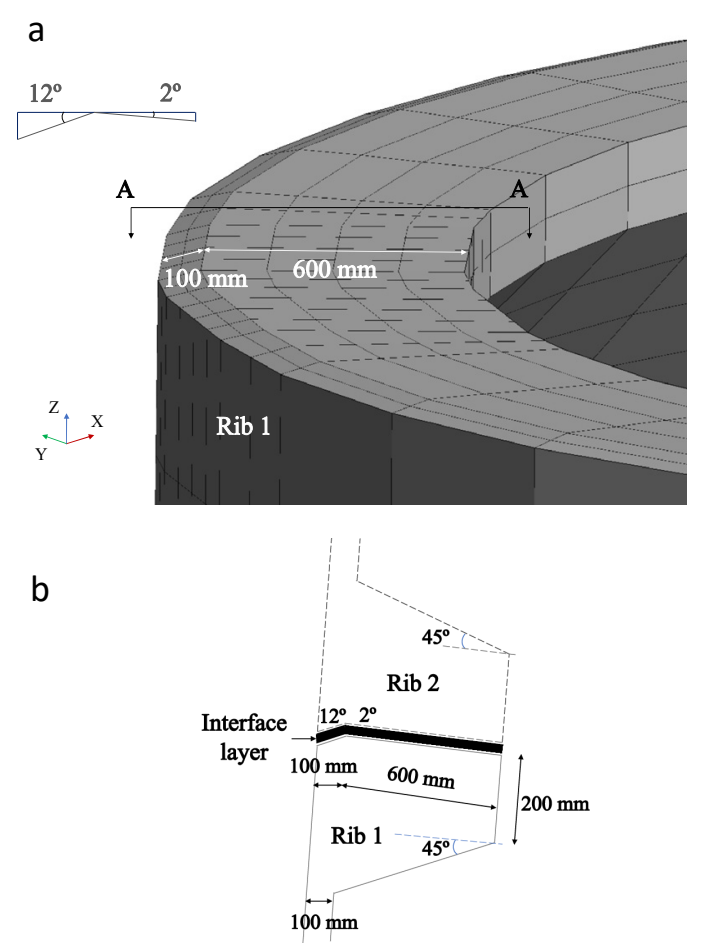

Figure 4. Geometry of the circumferential rib connecting two rings: (a) 3D and (b) 2D, cross section AA.

Solid hexahedra FE of 8 nodes are used to simulate the SFRC, with $2 \times 2 \times 2$ Gauss Legendre integration scheme. A maximum of 2 cracks is allowed to form at each integration point, with a threshold angle of 30 degrees for the new crack formation $\left(2^{\text {nd }} \mathrm{crack}\right)$. For assuring the results to be independent of the $\mathrm{FE}$ mesh refinement, a crack bandwidth equal to the cubic root of the volume of the integration point (IP), is adopted. The crack shear stress transfer is simulated through incremental approach. The CFRP bars and steel cables are modelled with 2-noded 3D embedded FE cable (with perfect bond). Interface finite elements of 8 nodes with $2 \times 2$ GaussLobato integration scheme are adopted to model the concrete-concrete contact between consecutive SFRC rings (ring 1 and ring 2). An additional linear layer of SFRC ( $1 \mathrm{~m}$ thick) is modelled (Fig. 3b) to avoid the development of unrealistic stress fields and severe cracking on the SFRC rings, where the real tower equivalent loads are applied (top of ring 2). Furthermore, a stiff steel plate is also connected to this extra linear-elastic SFRC layer to receive the equivalent loads and to transfer them on the tower.

According to the technical data sheet of the products, the adopted steel cables and connectors have $40 \mathrm{~mm}$ diameter, yield strength of $1147 \mathrm{MPa}$ and modulus of elasticity of 191
GPa. The CFRP bars have $30 \mathrm{~mm}$ diameter, tensile strength of $2400 \mathrm{MPa}$ and a modulus of elasticity of $270 \mathrm{GPa}$. The SFRC developed in a parallel research [8] has a compressive strength of $64 \mathrm{MPa}\left(f_{\mathrm{cm}}\right)$ and tensile strength of $6.77 \mathrm{MPa}\left(f_{t}\right)$, with modulus of elasticity of $42.15 \mathrm{GPa}\left(E_{c m}\right)$ obtained through experimental tests. The influence of fibre orientation on the post-cracking behaviour of SFRC was assessed by performing three point notched beam bending tests with series of specimens for fibre orientation intervals $\left[0-15^{\circ}\right.$ [, $\left[15-45^{\circ}\right.$, [ $[45-$ $75^{\circ}$ [ and $\left[75-90^{\circ}\right]$. By inverse analysis of the obtained results, the quadri-linear tensile softening diagram shown in Fig. 5a was obtained to model the fracture mode I propagation of the SFRC (presented in Table 3 of section 4.2, [10]. For the present simulations, the fibres are considered to have the best orientation towards the crack planes formed in the tower, which obliges appropriate casting technology for assuring preferential orientation of fibres in the longitudinal axis of a ring. However, the influence of fibre orientation on the response of the tower is assessed in a parametric study described in section 4.2. Due to relatively low compressive strain level in the installed SFRC rings with high compressive strength, it is assumed to behave in the elastic stage of the compression regime. The tension and compression behaviour of steel reinforcement (cables and connectors) is simulated by the stress-strain diagram represented in Fig. 5b. More details of the models for the FRC and reinforcements can be found in [11] and in [12], while the constitutive law of the interface finite elements is described in [13]. In the current analysis, the interface elements are assigned the following properties: slip at the end of the linear bond-slip relationship is $0.5 \mathrm{~mm}\left(S_{0}\right)$, slip at the peak bond stress is $2.5 \mathrm{~mm}\left(S_{m}\right)$, material cohesion of $1 \mathrm{MPa}$, friction angle as $37^{\circ}$, parameter defining pre-peak bond stress-slip relation is $\alpha_{1}=1$, parameter defining postpeak bond stress-slip relation $\alpha_{2}=1$ and a normal stiffness $\left(K_{n}\right)$ of $2.0 \times 10^{7} \mathrm{~N} / \mathrm{mm}$.

\section{Results}

\subsection{Simulations of the Model ' $t$ _s1'}

The loads acting on the global model are transmitted to the stiff loading plate placed on top part of the analysed model, shown in Fig. 4b, whose equivalent force and moments are shown in Table 2, factored according to Eq. (3).

The force vs. displacement of the "t_s1" model in X-direction is shown in Fig. 6a, where the displacement is measured on the top central node of the steel loading plate and the force as the summation of reaction forces at the base. Fig. $6 \mathrm{~b}$ and $6 c$ present the crack pattern at the end of the analysis $(100 \%$ of $\left.F_{x}\right)$, on the bottom and top rings, respectively, where the maximum crack width is $0.18 \mathrm{~mm}$, which was obtained by multiplying the maximum crack normal strain to the crack bandwidth of the integration point where it is being evaluated. 

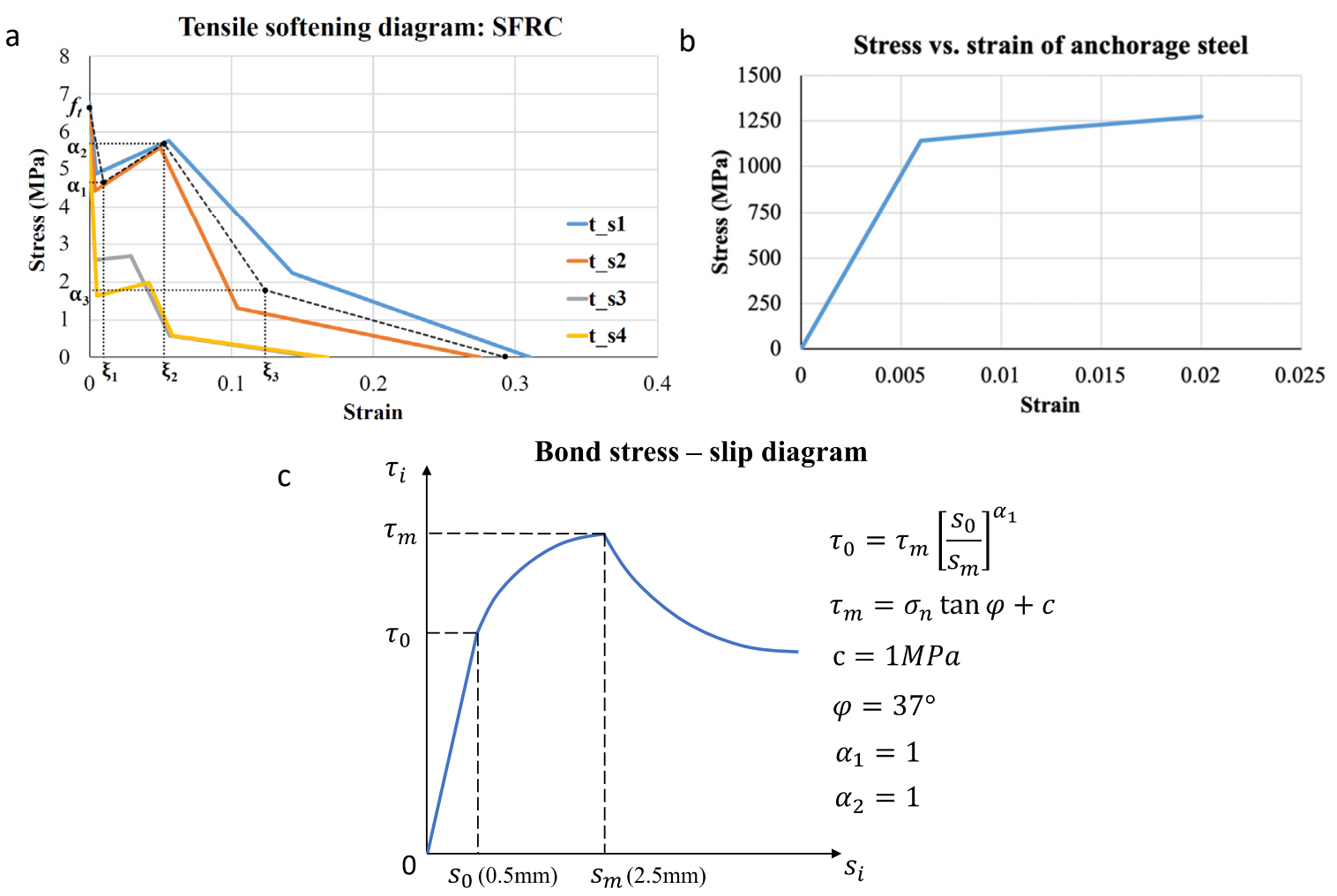

Figure 5. Numerical model: (a) Tensile strain softening diagram for SFRC with different orientation profiles; (b) Stress-strain diagram of the steel cables and connectors (c) Interface bond stress-slip diagram

Table 2. Different loads considered for the analysis

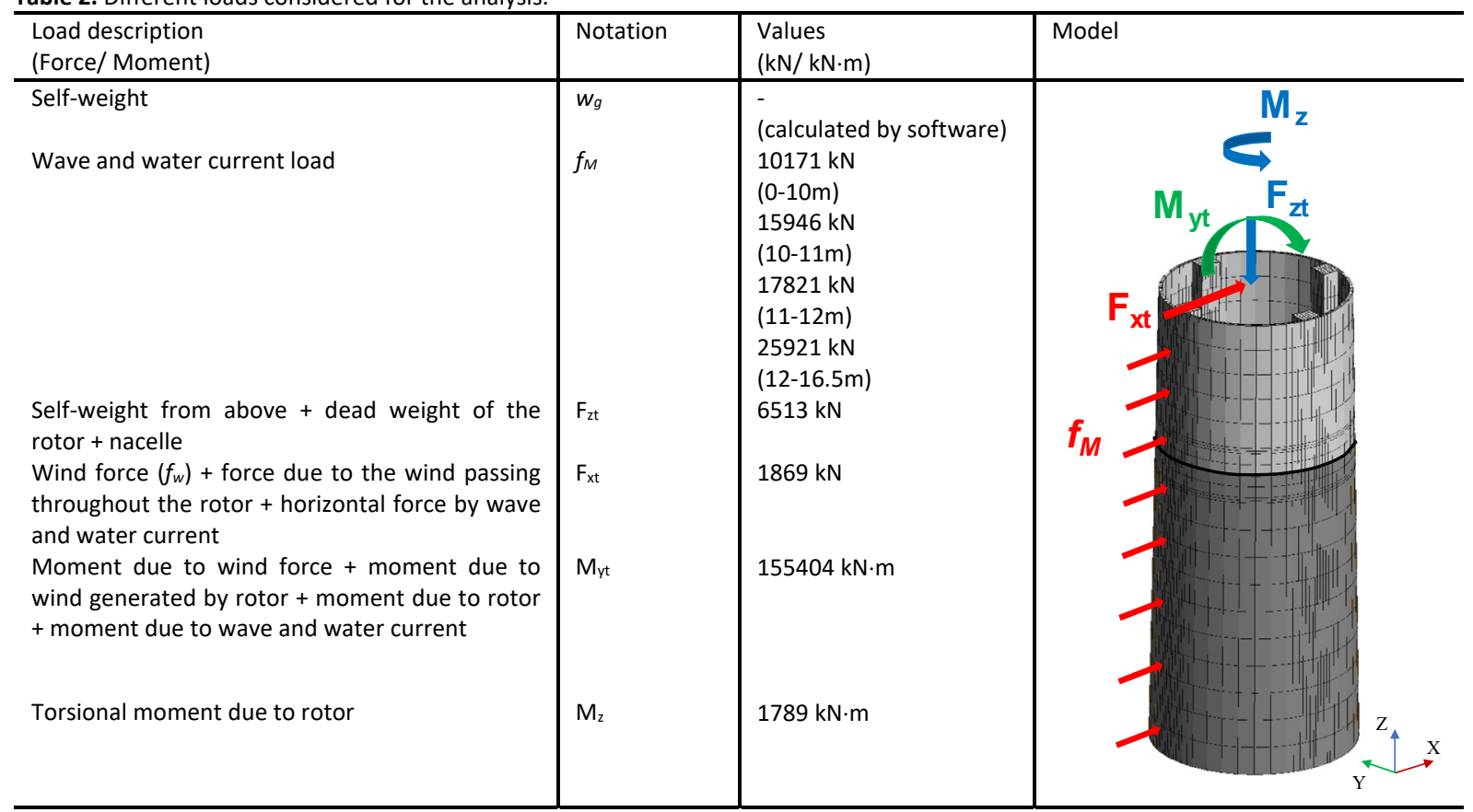


a

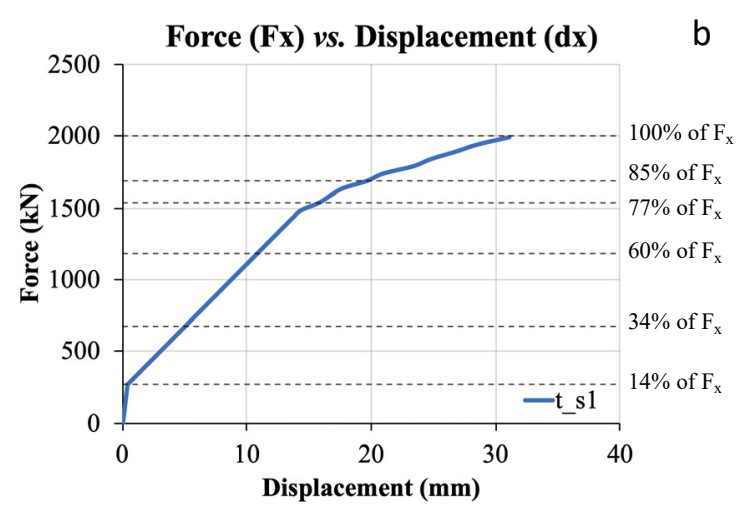

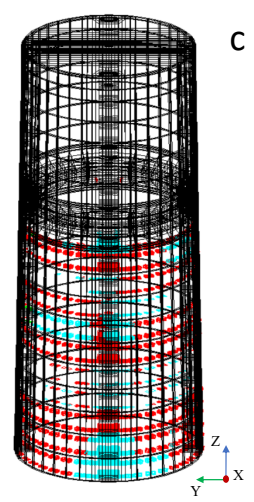

C

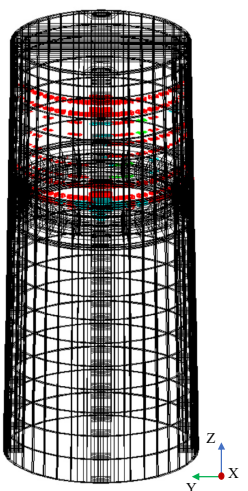

Figure 6. (a) Force vs. Deflection; Crack pattern: (b) bottom ring and (c) top ring, model "t_s1" (crack status: opening in red colour; reopening in cyan colour).

a

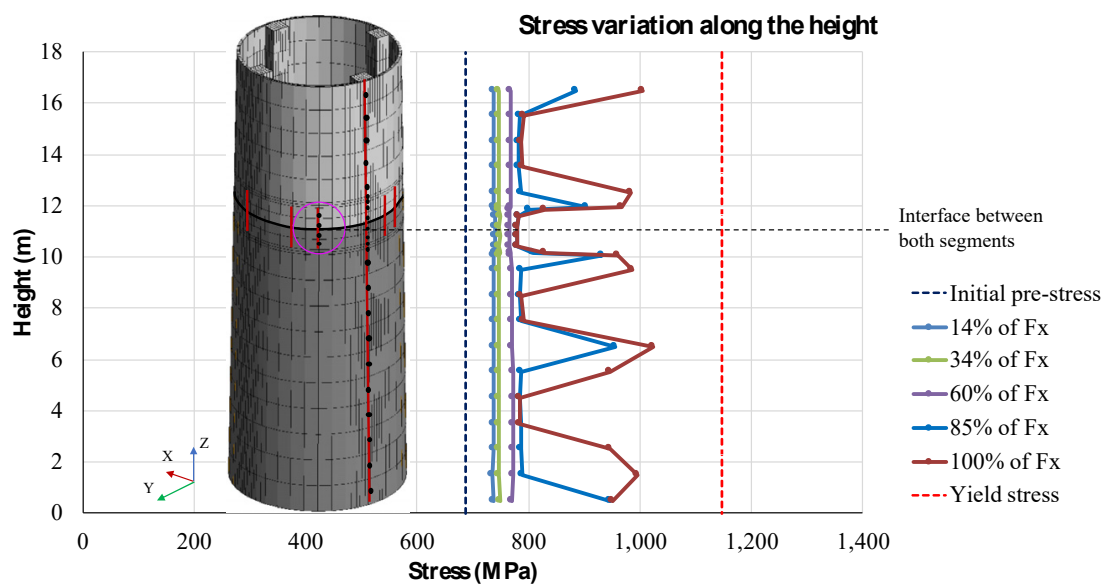

b

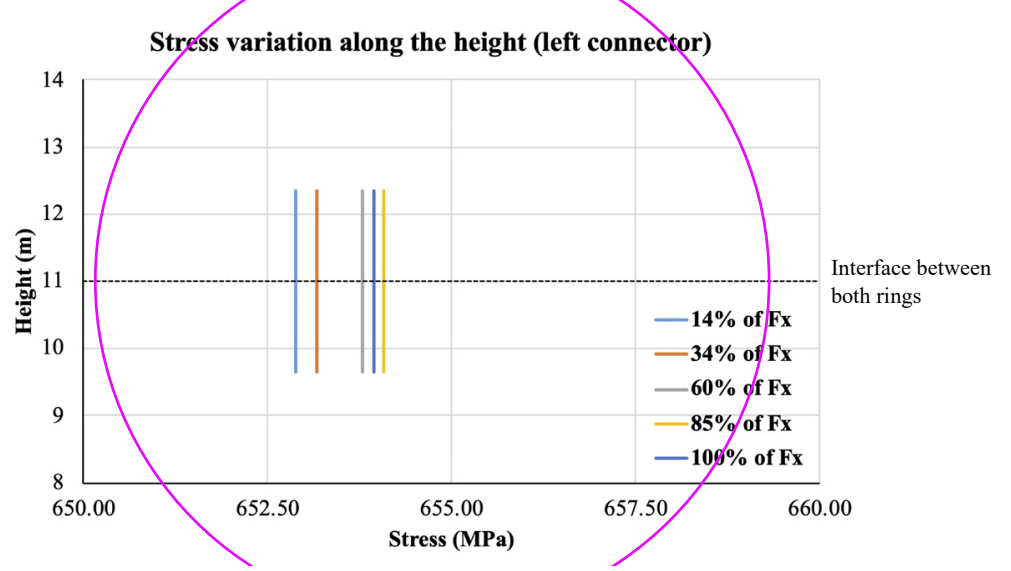

C

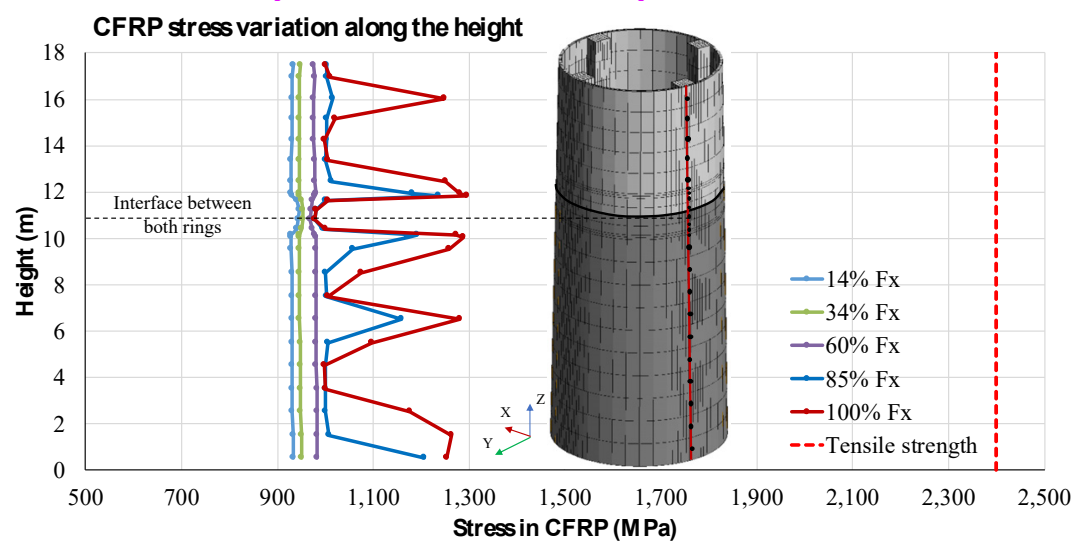

Figure 7. Evolution of the stress field in the: (a) post-tensioned steel cables; (b) post-tensioned steel connectors and (c) pre-tensioned CFRP bars, for different load combinations, model "t_s1". 
a

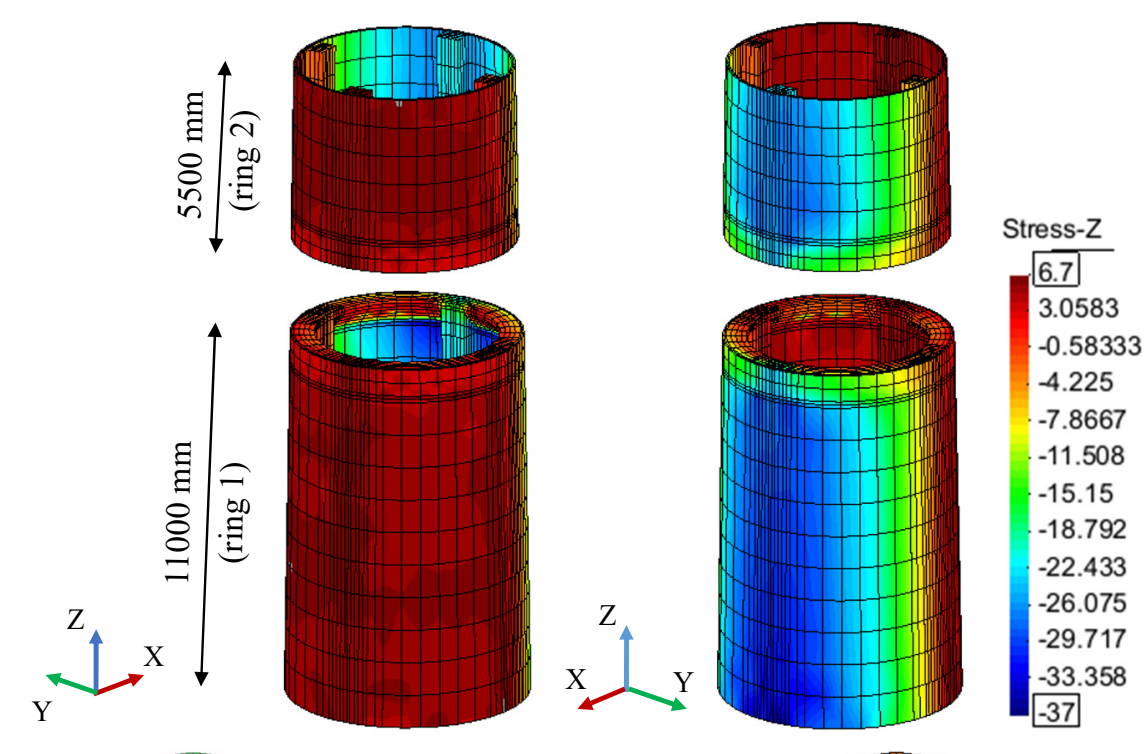

b
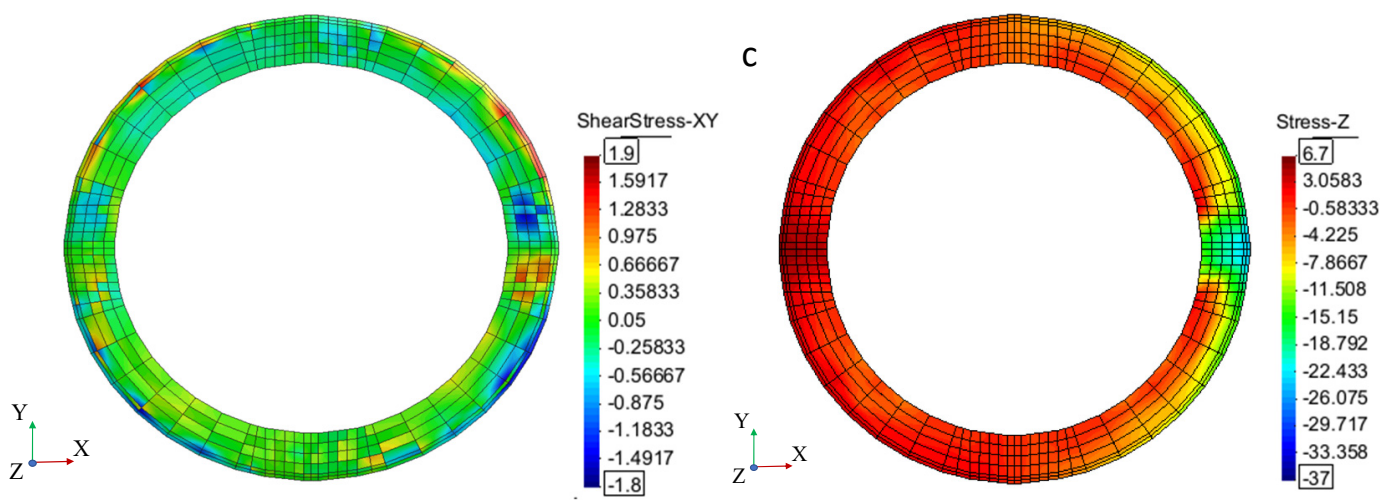

Figure 8. Model "t_s1": (a) Z-stress field; (b) shear stress field (interface layer) and (c) Orthogonal stresses interface layer) (all values are in $\mathrm{MPa})$.

Fig. 7 shows the evolution of the stresses along the height of the tower in the post-tensioned steel cables (Fig. 7a), in the steel connectors (Fig. 7b) and in the pre-stressed CFRP bars (Fig. 7c) at different IP (black dots on the tower) for the indicated load levels (represented in Fig. 7). Each steel connector is simulated by a single element with 5 integration points, connecting two elements of SFRC (top and bottom ring). At the interface, the steel cables are connected by the first point of the element in ring 1 (bottom) and the second point of the element in ring 2 (bottom), simulating the continuity. Post-tensioned stresses of $60 \%$ of the yield stress were introduced in both the steel connectors and steel cables. According to the results, the maximum tensile stress in the post-tensioned steel cables and connectors did not attain the corresponding yield stress (1147 MPa). Similarly, in the CFRP reinforcement a maximum stress of $1290 \mathrm{MPa}$ is reached i.e., $54 \%$ of the tensile strength ( $2400 \mathrm{MPa}$ ) of the respective CFRP bar. Stress jumps are obtained at certain IP at later stages due to crack formation (after $77 \%$ of $F_{x}$ ), as can be derived from Fig. $6 \mathrm{~b}$ and $6 \mathrm{c}$. At the interface between the two rings, no stress jump has occurred, which is a consequence of the effective anchorage of the steel connectors (Fig. 6b) and concrete-concrete interlock mechanism. This indicates that the post-tensioned steel cables are not necessary and the CFRP bar diameter can be reduced or even replaced by
GFRP/Basalt bars, which faster significantly the costs and process of assembling the SFRC rings.

Fig. 8 shows the stress distribution in Z-direction (vertical) from two different views at the end of the analyses, $100 \% F_{x}$. The combination of forces and moments applied on the current model according to DNV for the considered combination (max. ULS: $F=1.0 G+1.35 E$ ), generate tensile stresses (positive values, maximum of $100 \%$ of $f_{t}$ ) on one half of the tower and compressive stresses (negative values, maximum of $58 \%$ of $f_{c m}$ ) on the other half, which justify the option for assuming linear behaviour for the SFRC. The maximum shear stress variation on the interface layer between the two rings is lesser than 1.9 MPa (Fig. 8b).

\subsection{Parametric analyses}

Parametric studies are performed to assess the influence of the connection between the rings on the following aspects:

a) SFRC fracture parameters, which are dependent on the fibre orientation;

b) Pre-stress level in the steel (cables and connectors) and CFRP reinforcement;

c) Shape of concrete-concrete interlock mechanism;

d) Friction angle of the concrete-concrete contact conditions; 
e) Cohesion of the concrete-concrete contact conditions.

\subsubsection{SFRC fracture parameters}

The post-cracking tensile capacity of SFRC depends significantly on the fibre orientation towards the crack crossing the fibres [10]. This influence was investigated experimentally for four different casting conditions of SFRC in order to promote different fibre orientation profiles and, consequently, different fracture mode I parameters, whose corresponding values, define the quadrilinear diagram represented in Fig. 5a, and indicated in Table 3 [10].

Fig. 9a shows the results of force vs. displacement for the four toughness classes of SFRC. It is verified that, after crack initiation, the load carrying capacity of the tower increases with the post-cracking tensile capacity provided by the most favourable fibre orientation profiles. However, the difference on the load carrying capacity is small for fibre orientation profiles up to $45^{\circ}$. More favourable fibre orientation profiles promote the occurrence of more diffuse crack patterns, but of smaller width (Fig. 10).

\subsubsection{Pre-stress level in the steel and CFRP reinforcements}

Table 4 presents the two analysed pre-stress scenarios (percentage of the yield stress in case of steel and percentage of the tensile strength in case of (FRP) for the steel and CFRP reinforcements. The force $v s$. deflection for both the towers are shown in Fig. 9b, where it is verified as expected, the load at crack initiation, as well as in the post-cracking stage, decreases with the increased prestress level. At a deflection of $27.6 \mathrm{~mm}$, the pre-stress scenario corresponding to the ' $\mathrm{t}$ - $\mathrm{t} 2$ ' provided an increase of tower's load carrying capacity of $5.35 \%$ regarding the pre-stress scenario ' $t$ t $t 1$ ', which was due to the lower number of cracks of smaller crack width in the 't_t2' (see Fig. 11).

\subsubsection{Shape of concrete-concrete interlock mechanism}

Two different geometric connections are examined to study the influence of inclinations on the contact faces of two adjacent SFRC rings. The first connection is inclined at $2^{\circ}$ inward angle and $12^{\circ}$ outward angle as shown in Fig. 12a, while the second is a planar contact, i.e., no interlock mechanism is provided (Fig. 12b). All the other geometric and material properties, and loading conditions are maintained the same in both cases.

Fig. 13 a shows the force $v s$. displacement of the models, with and without interlock mechanism at the concrete-concrete contact of two consecutive SFRC rings. It is verified that the interlock mechanism increases the tower load carrying capacity in the post-cracking stage of about a constant 3.5\% with respect to the corresponding planar contact tower. The interlock shear resisting mechanism provided by the nonplanar contact has decreased the stress level in the steel connectors (Fig. 13b). These favourable aspects provided by the non-planar concrete-concrete contact may be potentiated by optimizing the geometry of these contacts.
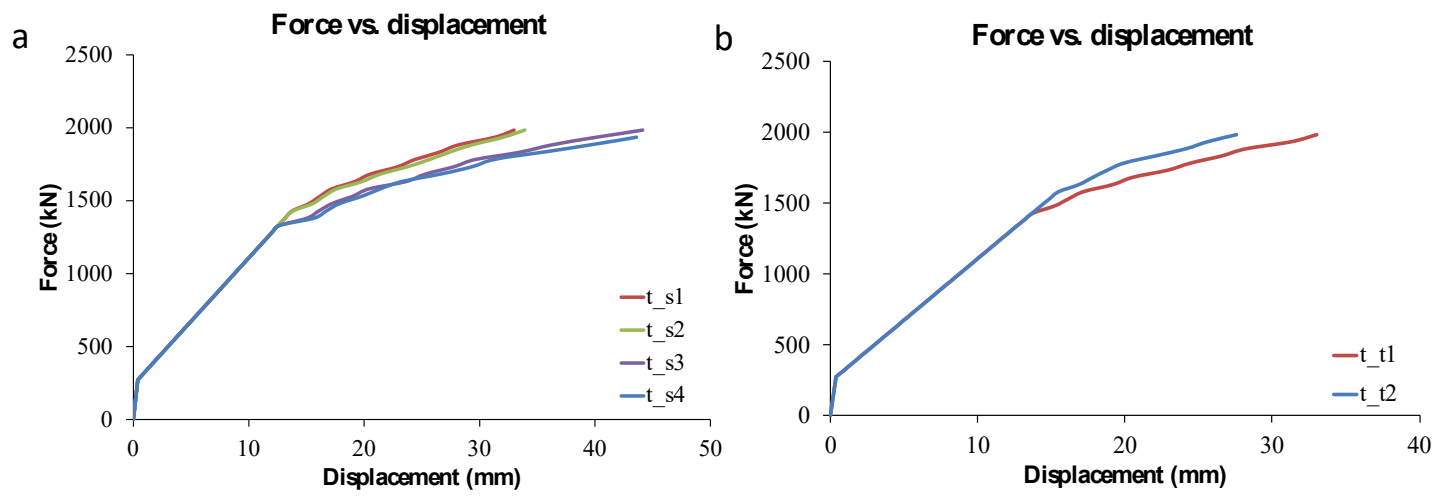

Figure 9. Influence on the force-deflection response of the simulated model of the: (a) post-cracking tensile capacity of SFRC (due to preferential fibre orientation profile); (b) pre-stress level on steel and CFRP reinforcements.

Table 3. SFRC fracture parameters defining a quadrilinear tensile stress - strain softening diagram for four distinct fibre orientation profiles.

\begin{tabular}{|c|c|c|c|c|c|c|c|c|c|}
\hline Model & $\beta$ & $\begin{array}{l}\alpha_{1} \\
{[-]}\end{array}$ & $\begin{array}{l}\alpha_{2} \\
{[-]}\end{array}$ & $\begin{array}{l}\alpha_{3} \\
{[-]}\end{array}$ & $\begin{array}{l}\xi_{1} \\
{[-]}\end{array}$ & $\begin{array}{l}\xi_{2} \\
{[-]}\end{array}$ & $\begin{array}{l}\xi_{3} \\
{[-]}\end{array}$ & $\mathrm{f}_{\mathrm{ct}} \quad[\mathrm{MPa}]$ & $\begin{array}{l}\mathrm{G}_{\mathrm{F}, \mathrm{I}} \\
{[\mathrm{N} / \mathrm{mm}]}\end{array}$ \\
\hline t_s1 & $0^{\circ}-15^{\circ}$ & 0.72 & 0.85 & 0.33 & 0.014 & 0.18 & 0.46 & 6.77 & 6.00 \\
\hline t_s2 & $15^{\circ}-45^{\circ}$ & 0.68 & 0.86 & 0.20 & 0.014 & 0.18 & 0.38 & 6.50 & 5.10 \\
\hline t_s3 & $45^{\circ}-75^{\circ}$ & 0.44 & 0.46 & 0.10 & 0.024 & 0.18 & 0.35 & 5.85 & 2.70 \\
\hline t_s4 & $75^{\circ}-90^{\circ}$ & 0.29 & 0.35 & 0.10 & 0.032 & 0.25 & 0.35 & 5.64 & 2.70 \\
\hline
\end{tabular}



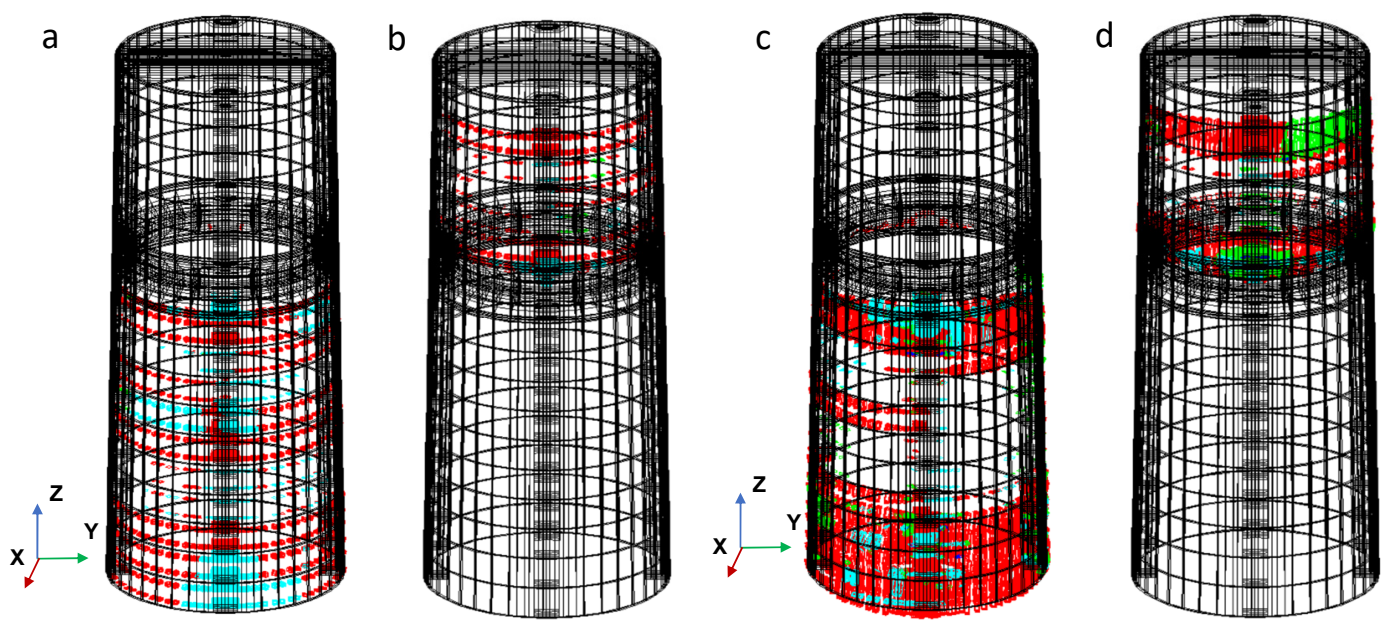

Figure 10.. Crack pattern: (a) Lower ring and (b) Upper ring of 't_s1'; (c) Lower ring and (d) Upper ring of 't_s4' (crack status: opening in red colour; closing in green colour, reopening in cyan colour).

Table 4. Adopted pre-stress percentage of the yield stress of the steel (cables and connectors) and CFRP reinforcement.

\begin{tabular}{lllll}
\hline Type of Reinforcement & $\begin{array}{l}\text { 't_t1' } \\
\text { Pre-stress } \\
(\%)\end{array}$ & percentage & Pre-stress (MPa) & $\begin{array}{l}\text { 't_t2' } \\
\text { Pre-stress } \\
(\%)\end{array}$ \\
\hline Steel & 60 & 756 & 75 & 945 \\
CFRP & 40 & 960 & 60 & 1440 \\
\hline
\end{tabular}
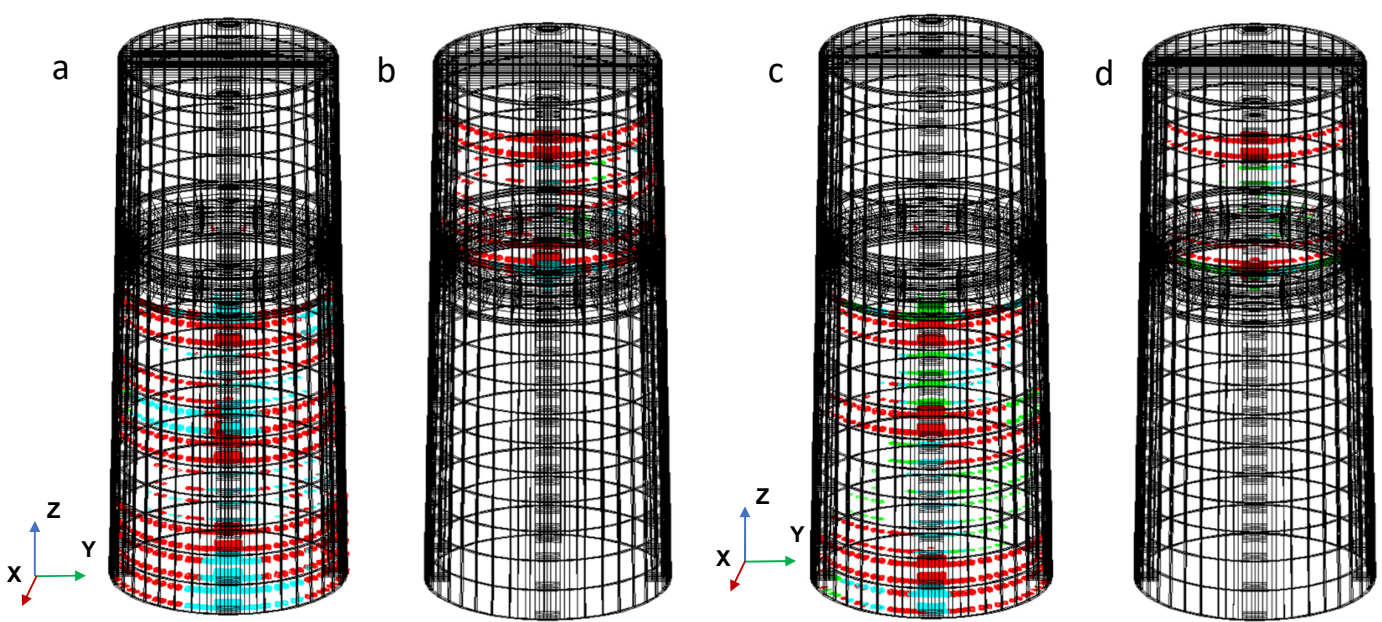

Figure 11. Crack pattern: (a) Lower ring and (b) Upper ring of 't_t1'; (c) Lower ring and (d) Upper ring of 't_t2' (crack status: opening in red colour; closing in green colour, reopening in cyan colour).

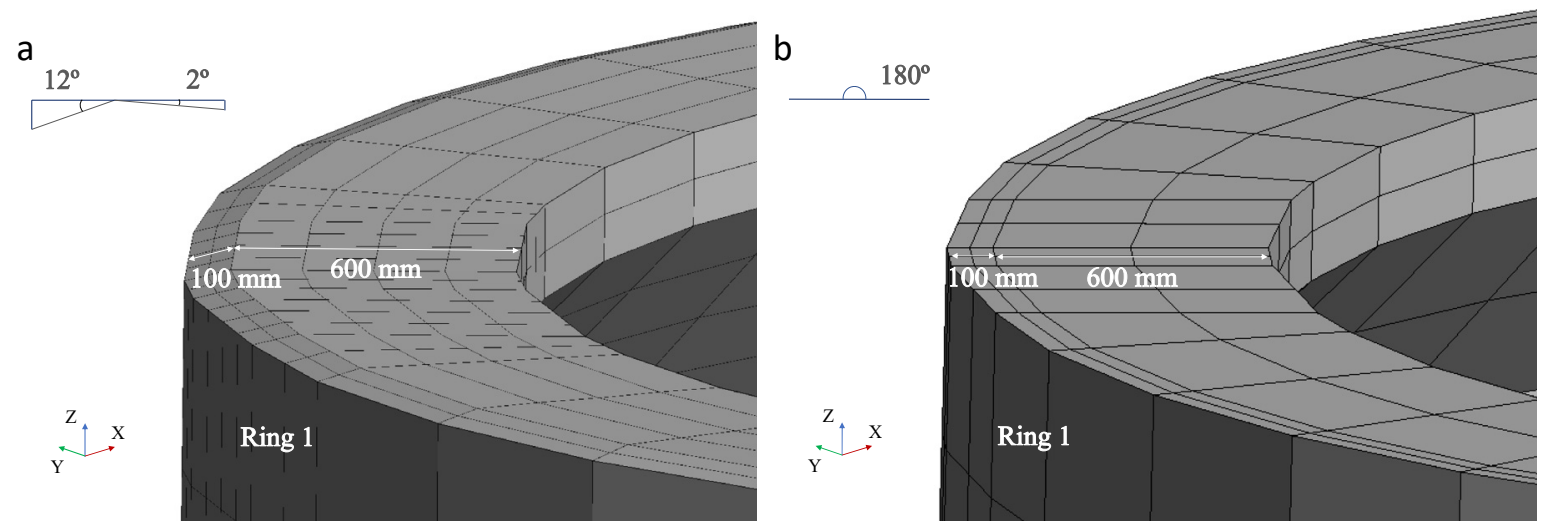

Figure 12. Models with (a) and without (b) interlock mechanism in the concrete-concrete contact of two adjacent SFRC rings. 

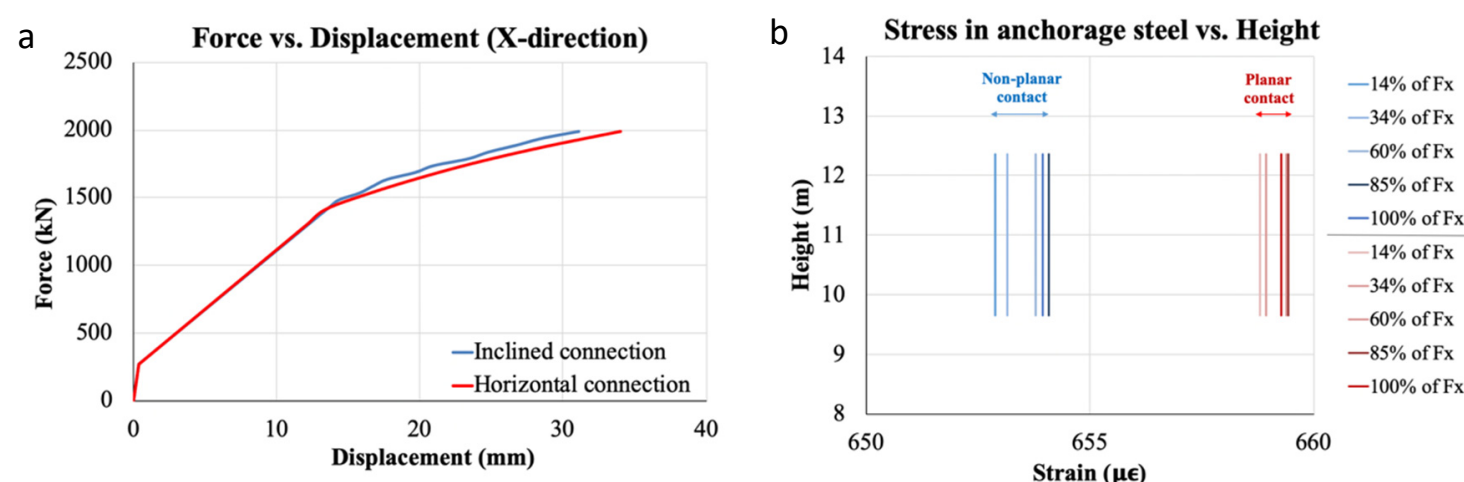

Figure 13. Influence of the concrete-concrete contact geometry on the (a) force vs. displacement and (b) stress level on the steel connectors during the loading process.

a

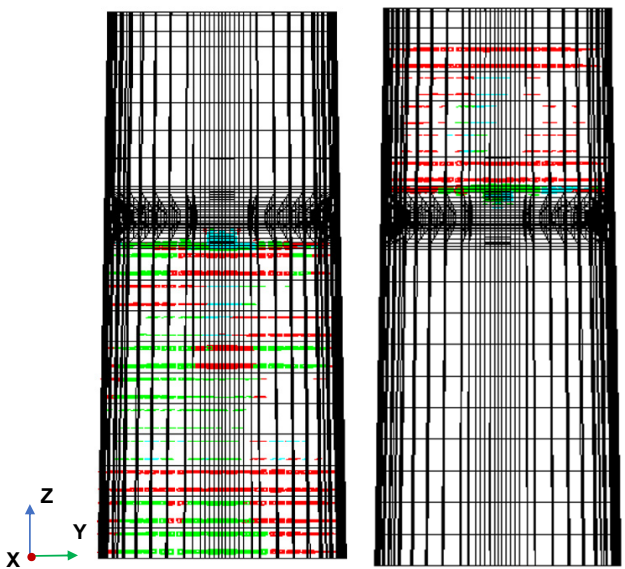

b

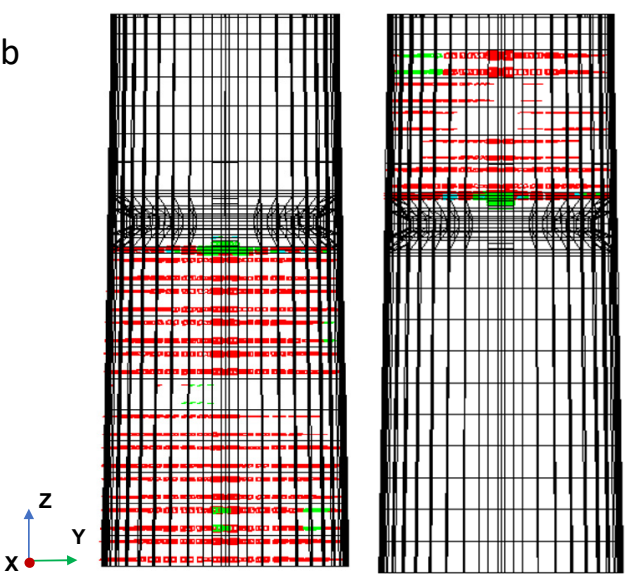

Figure 14. Crack pattern for concrete-concrete (a) non-planar, and (b) planar, contact conditions (crack status: opening in red colour; closing in green colour, reopening in cyan colour).

Table 5. Analysis for assessing the influence on the tower's behaviour of the friction angle and normal stiffness of the concrete-concrete contact.

\begin{tabular}{|c|c|c|c|c|}
\hline Model & $\begin{array}{l}\text { Friction angle, } \theta \\
\text { (degrees) }\end{array}$ & $\begin{array}{l}\text { Stiffness, } \quad K_{n} \\
(\mathrm{~N} / \mathrm{mm})\end{array}$ & $\begin{array}{l}\text { Cohesion, C } \\
(\mathrm{MPa})\end{array}$ & Remarks \\
\hline t_a1 & $37^{\circ}$ & \multirow{2}{*}{$2 \times 10^{7}$} & \multirow{6}{*}{1} & Runs $100 \%$ of $F_{x}$, no slip between rings are observed \\
\hline t_a2 & $0^{\circ}$ & & & Runs $100 \%$ of $F_{x}$, no slip between rings are observed \\
\hline t_a3 & $37^{\circ}$ & \multirow{2}{*}{$2 \times 10^{4}$} & & Runs $100 \%$ of $F_{x}$, slip between rings are observed \\
\hline t_a4 & $0^{\circ}$ & & & Runs $100 \%$ of $F_{x}$, slip between rings are observed \\
\hline t_a5 & $37^{\circ}$ & \multirow{2}{*}{$2 \times 10^{2}$} & & $\begin{array}{l}\text { Runs up to } 59 \% \text { of } F_{x} \text {, slip between rings are observed and } \\
\text { the analysis fails to converge }\end{array}$ \\
\hline t_a6 & $0^{\circ}$ & & & $\begin{array}{l}\text { Runs up to } 70 \% \mathrm{~F}_{\mathrm{x}} \text {, slip between rings are observed and the } \\
\text { analysis fails to converge }\end{array}$ \\
\hline
\end{tabular}

The crack pattern of these simulations at $100 \% \mathrm{~F}_{\mathrm{x}}(1989 \mathrm{kN})$ are presented in Fig. 14a and $14 \mathrm{~b}$ for the non-planar and planar contact conditions, respectively. It is verified the formation of higher number of cracks in the planar contact conditions in both upper and lower rings, with larger maximum crack width $(0.25 \mathrm{~mm}$ over $0.19 \mathrm{~mm})$. This is due to the larger displacement of planar contact model, as a result of which the tower is subjected to higher stresses and more cracks. In case of non-planar contact model, the additional shear resistance provided by the inclination reduces the deformation and cracks with respect to planar contact model.

\subsubsection{Friction angle of the concrete-concrete contact conditions}

The influence of friction angle on the concrete-concrete contact conditions simulated through the constitutive law of the interface $\mathrm{FE}$ is analysed by adopting the values presented in Table 5, while maintaining the same values for the other parameters. In the first two simulations, the friction angle is varied with $0^{\circ}$ and $37^{\circ}$, and a constant normal stiffness of $2 \times 10^{7} \mathrm{~N} / \mathrm{mm}$. With this relatively high normal stiffness, the influence of the friction angle on the relevant behavioural aspects of the tower is negligible (Fig. 15: model ' $t$-a1' and 't_a2'), since sliding is almost null regardless of the friction angle (Fig. 16a, b). However, reducing the normal stiffness to $2 \times 10^{4} \mathrm{~N} / \mathrm{mm}$, the influence of the friction angle is already 
significant (model ' $\mathrm{t}$ a3' and ' $\mathrm{t}$ a4' in Table 5), since a maximum variation of sliding between the two analysis was $2.5 \%$ and with respect to ' $t$-a 1 ' is $9.4 \%$ ('t_a3') and $6.7 \%$ ('t_a4'). The last two analysis in Table 5, are performed with very low normal stiffness of $2 \times 10^{2} \mathrm{~N} / \mathrm{mm}$, where the models have very large displacements and are almost distorted.

The force vs. deflection of all these analyses are presented in Fig. 15 , where the models with high stiffness $\left(2 \times 10^{7} \mathrm{~N} / \mathrm{mm}\right)$ had almost no influence in the global response. The models with low stiffness $\left(2 \times 10^{4} \mathrm{~N} / \mathrm{mm}\right)$ increased the overall deformation by $5.6 \%$ and $3.8 \%$, and the last two analysis with very low stiffness $\left(2 \times 10^{2} \mathrm{~N} / \mathrm{mm}\right)$ even failed to complete the analysis, due to large displacements. These analyses shows the impact on the response of the tower, for the variation of friction angle which is dominant only for lower values of stiffness.

\subsubsection{Cohesion of the concrete-concrete contact conditions}

The effect of the cohesion of the concrete-concrete contact conditions simulated through the constitutive law of the interface FE is analysed by adopting two values, $0 \mathrm{MPa}$ and 1 MPa (the value recommended by fib Model Code 2010 [14]), while the remaining parameters are maintained the same. The analysis were grouped in three series in order to assess also the influence of the normal stiffness, as shown in Table 6.
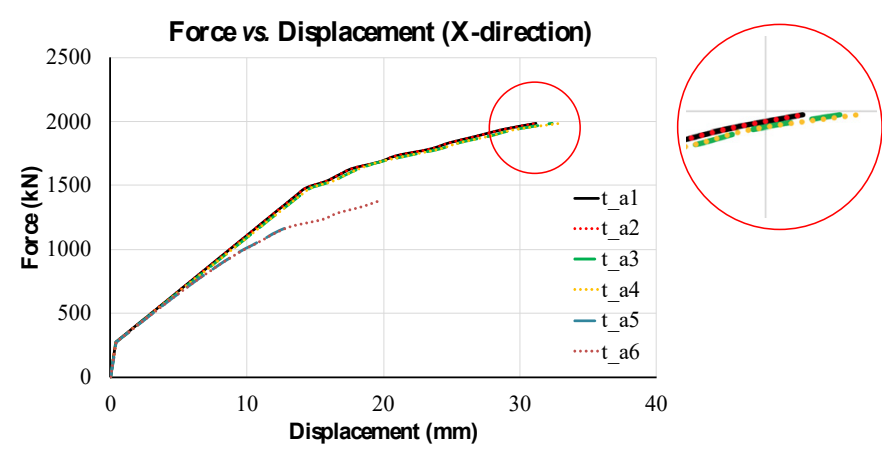

Figure 15. Force vs. displacement influence of friction angle on the concrete-concrete contact condition.
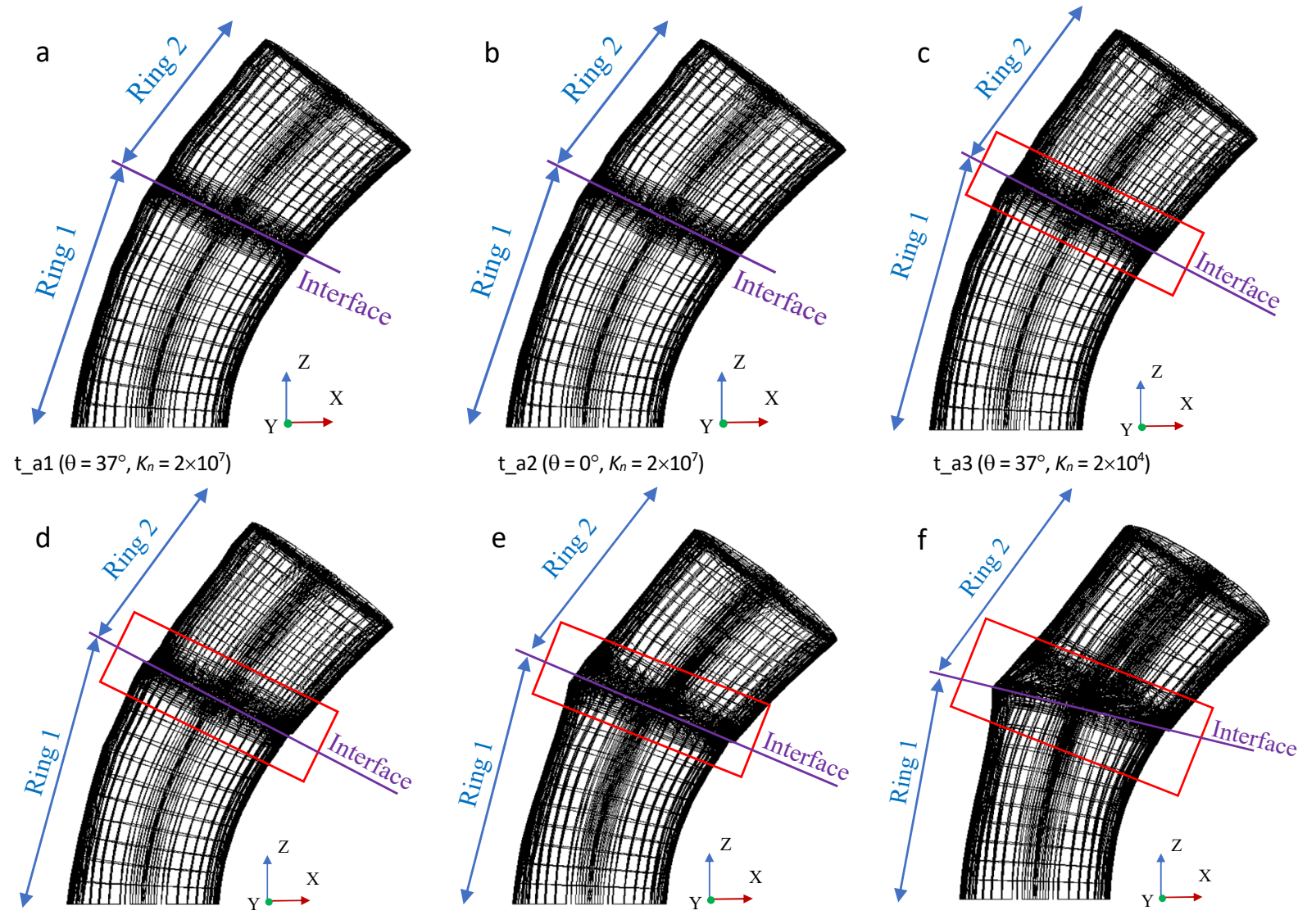

t_a5 $\left(\theta=37^{\circ}, K_{n}=2 \times 10^{2}\right)$

t_a6 $\left(\theta=0^{\circ}, K_{n}=2 \times 10^{2}\right)$

Figure 16. Influence of the friction angle of the concrete-concrete contact on the deformation of models for normal stiffness of: (a)-(c) $2 \times 10^{7}$ $\mathrm{N} / \mathrm{mm}$, and (d)-(f) $2 \times 10^{4} \mathrm{~N} / \mathrm{mm}$. 
Table 6. Analysis for assessing the influence on the tower's behaviour of the cohesion and normal stiffness of the concrete-concrete contact.

\begin{tabular}{|c|c|c|c|c|}
\hline Model & $\begin{array}{l}\text { Cohesion, } \mathrm{C} \\
(\mathrm{MPa})\end{array}$ & $\begin{array}{l}\text { Stiffness, } \\
(\mathrm{N} / \mathrm{mm})\end{array}$ & $\begin{array}{l}\text { Friction angle, } \theta \\
\text { (degrees) }\end{array}$ & Remarks \\
\hline t_c1 & 1 & \multirow{2}{*}{$2 \times 10^{7}$} & \multirow{6}{*}{$37^{\circ}$} & Runs $100 \%$ of $F_{x}$, no slip between rings are observed \\
\hline t_c2 & 0 & & & Runs $100 \%$ of $F_{x}$, no slip between rings are observed \\
\hline t_c3 & 1 & \multirow{2}{*}{$2 \times 10^{4}$} & & Runs $100 \%$ of $F_{x}$, no slip between rings are observed \\
\hline t_c4 & 0 & & & Analysis fails to converge even the first load combination \\
\hline t_c5 & 1 & \multirow[t]{2}{*}{$2 \times 10^{2}$} & & $\begin{array}{l}\text { Runs up to } 59 \% \text { of } F_{x} \text { and fails to converge after, slip between } \\
\text { rings are observed }\end{array}$ \\
\hline t_c6 & 0 & & & Analysis fails to converge even the first load combination \\
\hline
\end{tabular}

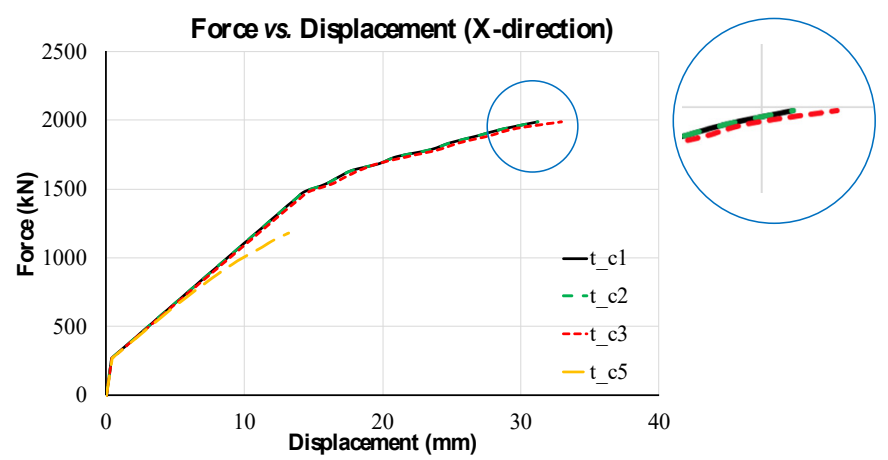

Figure 17. Force vs. displacement influence on cohesion of concrete-concrete contact conditions.
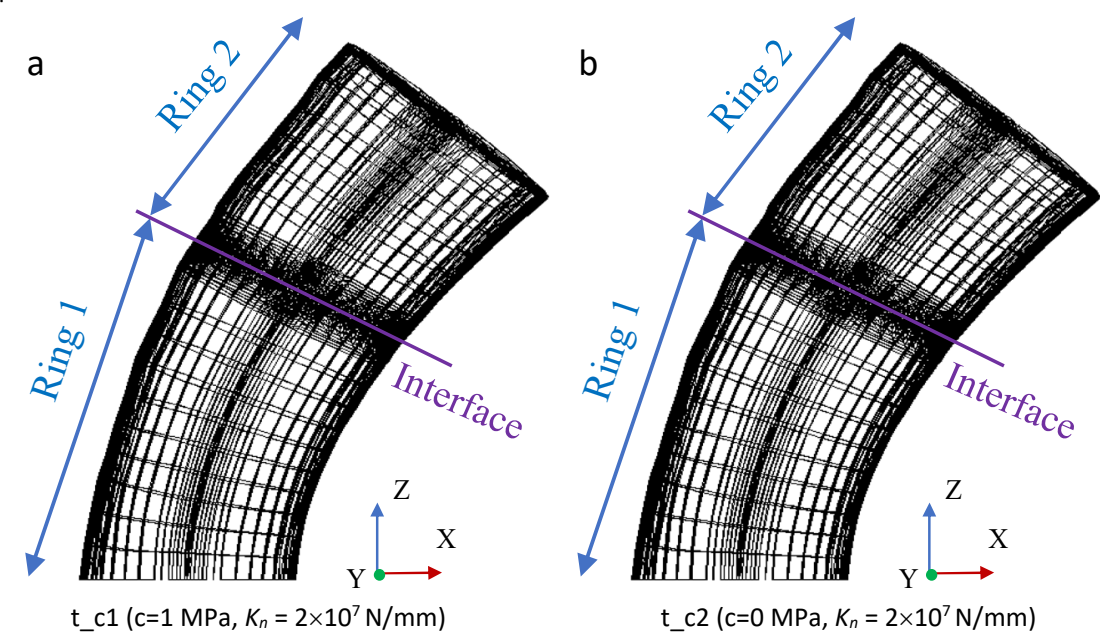

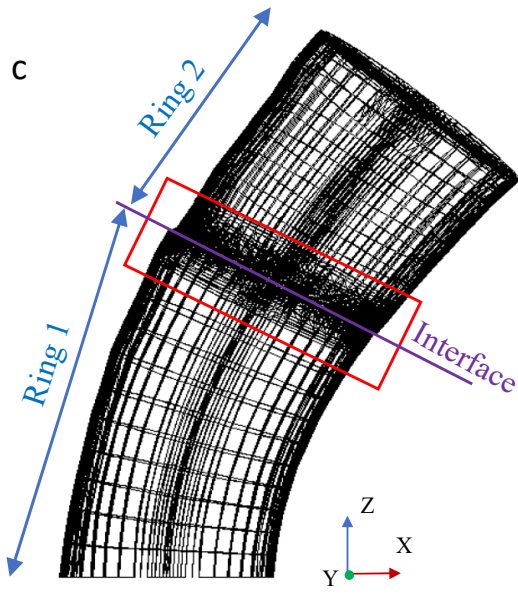

t_c3 (c=1 MPa, $\left.K_{n}=2 \times 10^{4} \mathrm{~N} / \mathrm{mm}\right)$

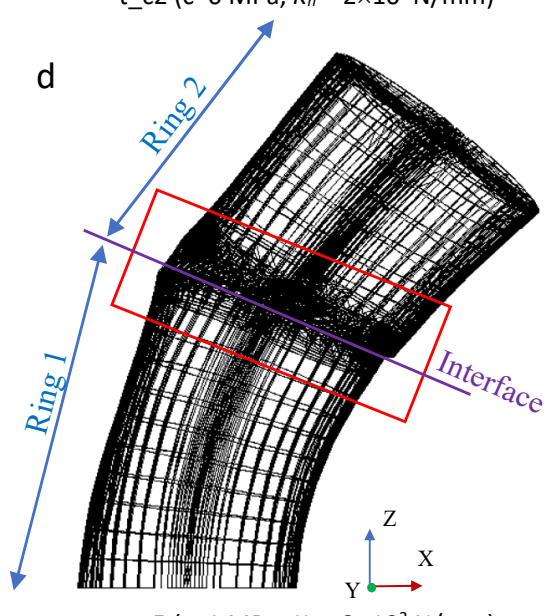

t_c5 (c=1 MPa, $\left.K_{n}=2 \times 10^{2} \mathrm{~N} / \mathrm{mm}\right)$

Figure 18. Deformation of models with different cohesive values. 
The first two models 't_c1' and 't_c2' with high stiffness $\left(2 \times 10^{7} \mathrm{~N} / \mathrm{mm}\right)$, has almost no influence on the structural performance of the towers, shown in Fig. 17 (force vs. displacement) and on the deformation plots where no slip is observed, Fig. 18 (a, b). Reducing the stiffness to $2 \times 10^{4} \mathrm{~N} / \mathrm{mm}$ in ' $t$ _c3' the overall deformation is increased by $5.6 \%$ and a slip of $1.01 \mathrm{~mm}$ takes place between the rings, Fig. $18 \mathrm{c}$. However, further reducing the stiffness to $2 \times 10^{2} \mathrm{~N} / \mathrm{mm}$, the analysis of model ' $t$ _c5' stops at $59 \%$ of $F_{x}$, with an increased slip of $1.26 \mathrm{~mm}$ between the rings i.e., $24.7 \%$ increase with respect to 't_c3' $\left(2 \times 10^{4} \mathrm{~N} / \mathrm{mm}\right)$. The force vs. displacement graphs of all the models are shown in Fig. 17. Even though, the overall stiffness variation between ' $t$ _c1' and ' $t$ _c3' is not pronounced, the stiffness variation between ' $t$ - $c 1$ ' and ' $t$ - $c 5$ ' is quite drastic. In case of models ' $t$ _c4' and ' $t$ _c6' both the analysis fail to converge due to the absence of cohesion, lower normal stiffness and higher displacement between the concrete-concrete contact condition.

\section{Conclusions}

According to the results obtained from the FE numerical analyses, the following conclusions are summarised. However, the validation of the numerical work will be further explored in the next stages of the research after executing experimental work in the laboratory.

- The proposed material-structural concept of offshore wind tower, combining SFRC, prestressed CFRP bars, post-tensioned steel cables, and post-tensioned steel connectors greatly reduces the wall thickness by $\left(1 / 6^{\text {th }}\right)$, with respect to conventional concrete construction;

- The structural behaviour of this tower was assessed by performing material nonlinear analysis and considering some of the most design governing loading conditions, having accomplished the most unfavourable combination for ULS;

- The maximum crack width obtained in the model with the SFRC of highest post-cracking tensile capacity (due to the consideration of fibre orientation) was $0.18 \mathrm{~mm}$, for ULS conditions indicating that no corrosion problems is expected even by adopting steel fibres;

- None of the steel reinforcements have yielded nor they are closer to the yielding value, even though some variations are observed at crack locations, they are within the corresponding yield values;

- By managing the pre-stress level applied to the CFRP bars and steel strands, the stiffness of the response of the tower can be adapted;

- Inclined connection between the rings has better performance in terms of reduced stresses in the posttensioned steel connectors, overall deformation and smaller maximum crack width;

- The influence of the friction angle and cohesion of the concrete-concrete contact conditions between consecutive SFRC rings has only a detrimental influence of the tower's behaviour if relatively small normal stiffness is assumed for the contact conditions.

\section{Acknowledgements}

The authors acknowledge the support provided by FEDER funds through the Operational Programme for Competitiveness and Internationalization - COMPETE and by national funds through FCT (Portuguese Foundation for Science and Technology) within the scope of the project InOlicTower, POCI-01-0145-FEDER-016905 (PTDC/ECMEST/2635/2014).

\section{CRediT authorship statement}

Chandan C. Gowda: methodology, software, validation, formal analysis, investigation, data curation, writing - original draft, writing - review and editing, visualization; Fabio P. Figueiredo: methodology, software, validation, resources, data curation, writing - original draft, supervision; Joaquim A. O. Barros: conceptualization, methodology, resources, data curation, writing - review and editing, visualization, supervision, project administration, funding acquisition; $\mathbf{A}$. Ventura-Gouveia: conceptualization, funding acquisition.

\section{References}

[1] G. Giebel and C. B. Hasager, An Overview of Offshore Wind Farm Design. Denmark, 2016.

https://doi.org/10.1007/978-3-319-39095-6 19

[2] GWEC, GWEC Global Wind 2017 Report - A snapshot of top wind markets in 2017: Offshore wind. 2017.

[3] S. Malhotra, Selection, design and construction of offshore wind turbine foundations. 2011 https://doi.org/10.5772/15461

[4] S. Malhotra, Design and construction considerations for offshore wind turbine foundations, in: Proceedings of the International Conference on Offshore Mechanics and Arctic Engineering - OMAE, 2007 (5) : 635-647. https://doi.org/10.1115/OMAE2007-29761

[5] H. Ma, J. Yang, and L. Chen, Numerical analysis of the long-term performance of offshore wind turbines supported by monopoles. Ocean Eng (2017) 136: 94-105. https://doi.org/10.1016/i.oceaneng.2017.03.019

[6] F. P. Figueiredo, M. E. Hassanabadi, J. A. O. Barros, and A. VenturaGouveia, A simplififed design approach of offshore wind towers. Report. 2018.

[7] DNV, DNV-OS-J101 Design of offshore wind turbine structures. 2014, 212-214.

[8] F. P. Figueiredo, J. A. O. Barros, and A. V. Gouveia, Nonlinear Analysis of offshore Wind Towers in prefabricated segments of prestressed Fibre Reinforced Concrete, 2020.

[9] A. Ventura-Gouveia, J. A. O. Barros, A. F. M. Azevedo, and J. M. SenaCruz, Multi-Fixed smeared 3D crack model to simulate the behavior of fiber reinforced concrete structures. CCC2008-Challenges Civ. Constr (2008): 11.

[10] A. Abrishambaf, J. A. O. Barros, and V. M. C. F. Cunha, Timedependent flexural behaviour of cracked steel fibre reinforced selfcompacting concrete panels. Cem Concr Res (2015) 72: 21-36. https://doi.org/10.1016/i.cemconres.2015.02.010

[11] J. A. O. Barros, M. Breveglieri, A. Ventura-Gouveia, G. M. Dalfré, and A. Aprile, Model to simulate the behavior of $\mathrm{RC}$ beams shear strengthenend with ETS bars. Fram Fract Mech Concr Concr Struct (2013): 505-516.

[12] A. V. Gouveia, Constitutive models for the material nonlinear analysis of concrete structures including time-dependent effects. University of Minho, Guimaraes, Portugal, 2011.

[13] T. D. S. Valente, Advanced numerical models for analysis of the behaviour of structures strengthened with an innovative technique. University of Minho, Portugal, 2019.

[14] fib CEB-FIP, fib Model Code for Concrete Structures 2010. Wilhelm Ernst \& Sohn, 2010 